\title{
The overall precision test for near infrared scanning and reference method for the determination of soluble solids content and $\mathrm{pH}$ of mango for processing factory
}

\author{
Nphatsanan Saksangium ${ }^{1 *}$ and Panmanas Sirisomboon ${ }^{1}$ \\ ${ }^{1}$ King Mongkut's Institute of Technology Ladkrabang, Department of Agricultural Engineering, \\ Faculty of Engineering, Bangkok, Thailand.
}

\begin{abstract}
Near infrared (NIR) spectroscopy is a rapid technique for nondestructive testing. Mango is popular fruit in Thailand. Therefore, The main aim of this paper is to report an overall precision of the NIR spectroscopy instruments and reference methods for determination at the beginning of the experiment for prediction models development to be in the mango applied processing factory.. Results showed that the repeatability of FT-NIR spectrometer and UV-VIS-NIR spectrometer were 0.00191 and 0.00529 , respectively. The reproducibility of FT-NIR spectrometer and UV-VIS-NIR spectrometer were 0.00323 and 0.03561 , respectively. Repeatability of reference test of TSS and $\mathrm{pH}$ were 0.1657 and 0.0827 . Therefore, the $\mathrm{R}^{2} \mathrm{max}$ of TSS and $\mathrm{pH}$ were 0.9825 and 0.9504 which indicates that it is possible to develop NIR model for prediction of total soluble solids and $\mathrm{pH}$.
\end{abstract}

\section{Introduction}

Mango is a tropical fruit that is important for the economy of Thailand. There are more than 100 cultivated varieties. Mango can adapt to the climate of Thailand as well. It can grow almost the whole country. Therefore mango is a fruit plant that is popularly grown and consumed as the number one of all fruits in Thailand.[1]. Thailand has a significant portion of its income from exports of agricultural products and mangoes are one of the country's most important exports, which can be seen from the amount of mangoes exported in 2018 which have worth approximately 50 million USD [2].

Because Thai mango has good taste attracting foreign consumers to eat and accept but with mango picking before the harvest season, the mango tasting is not sweet but sour. Therefore causing damage to Thai mango exports which has problems with separating sweet mango from non-sweet mango. This requires experience and expertise in sorting. The processing of mangoes is another way to make value added of mango which can be consume both domestically and internationally. The mangoes that contain a lot of water and a lot of fiber (juicy type) is suitable for processing to be beverages such as mango juice. In addition,

* Corresponding author: Maenphatsanan.sa@gmail.com 
the other processed mangoes are pickled mangoes, crystallized mango and dried mangoes. The chemical properties of mangoes used in processing for quality control and assurance are total soluble solids, acidity and $\mathrm{pH}$. According to the survey, there are at least 230 factories for processing mangoes, of which this factory has a production capacity of more than 100 tons per day [3].

Near Infrared Spectroscopy (NIRS) is one technique that is popular and widely accepted for measuring the internal quality of fruits where the fruits can be scanned without damage[4]. Therefore the objective of this research was to test the possibility of scanning of mango with NIR in order to develop the model in the future by considering the repeatability and reproducibility of the scanning for the Thakolsri farm model. The precision of the instrument is measured by the value of repeatability and reproducibility of scanning. These can indicate the precision of the instrument. Repeatability of reference test. These can describe the precision of reference method The $\mathrm{R}^{2}$ Max is obtained there is an error only from the wet lab. No NIR error.

\section{Materials and methods}

\subsection{Materials}

Mango samples were from Thakolsri-Farm in Phetchabun, Thailand. There were 10 samples.

\subsection{NIR scanning of the mango}

The mango samples were scanned by FT-NIR spectrometer (MPA FT-NIR, Bruker Optik GmbH, Ettlingen, Germany) for offline scanning and UV-VIS-NIR spectrometer (AvaSpecULS2048- USB2-VA-50, AVANTES, Netherlands) for online scanning. For FT- NIR spectrometer, the sample were scanned between wavenumber of 12,500-4,000 cm-1 or 800 $-2500 \mathrm{~nm}$ ) with a resolution of $16 \mathrm{~cm}^{-1}$ in diffuse reflection mode. The scanning was completed 32 times per one average spectrum. Before each sample scanning, the gold used as a reference material was scanned for background. For UV-VIS-NIR spectrometer, the sample was scanned in the wavelength range of 200-1160 $\mathrm{nm}$ in diffuse reflection mode using Teflon as reference material. The scan time was $4.086 \mathrm{~ms}$ at an average of 100 times. The samples were scanned at a distance of throughout the sample length of $12 \mathrm{~cm}$ and average to 1 spectrum at the belt speed of $0.1 \mathrm{~m} / \mathrm{s}$. Fiber optics probe surface distance to the surface of sample was approximately $1-2 \mathrm{~cm}$. All scanning was conducted at air conditioning room temperature $\left(25 \pm 2^{\circ} \mathrm{C}\right)$.

\subsection{Repeatability and reproducibility test}

The repeatability and reproducibility of NIR scanning were determined by scanning on a sample. Samples were the 10 spectra scanned at the same position of an intact mango fruit and were the 9 spectra scanned on the fruit but reloaded at every scan. And the first 10 spectra were used for calculating the repeatability of scanning. The last spectrum of the first 10 scans and 9 spectra scanned with reloaded were used for calculation of the reproducibility. The 3 mangoes were used as 3 replication for the experiment. Then calculating the standard deviation (SD) value of the absorbance for the scanning. The 3 wavenumbers from whole spectrum including $970 \mathrm{~nm}, 1440 \mathrm{~nm}$ and $1900 \mathrm{~nm}$ [5] were selected and the average SD of absorbance in all wavenumbers were the repeatability of scanning of the instrument. 
The repeatability of the measured reference value corresponds to the standard deviation of the differences between the duplicates. On the other hand, the reproducibility of the measured reference value was the standard deviation of the differences between the duplicates, which were obtained from blind samples. Then the repeatability of measured reference value (Rep) was used to determine the maximum coefficient of determination $\left(\mathrm{R}^{2} \mathrm{max}\right)$, which was calculated using following formula

$$
\mathrm{R}_{\mathrm{Max}}^{2}=\frac{\mathrm{SD}_{\mathrm{y}}^{2}-\mathrm{Rep}^{2}}{S D_{\mathrm{y}}^{2}}
$$

Where SDy is the standard deviation of data of measured value in calibration set. $\mathrm{R}^{2} \max$ is possible only when there are no errors in the spectra or the model.

\section{Results and discussion}

\subsection{Repeatability and reproducibility of instrument}

Three wavenumber $10306 \mathrm{~cm}^{-1}(970 \mathrm{~nm})$ i.e. band of water[6], $6943 \mathrm{~cm}^{-1}(1440 \mathrm{~nm})$ i.e.band of sucrose and $6326 \mathrm{~cm}^{-1}(1580 \mathrm{~nm})$ band of starch were selected (Figure.1) in order to obtain the repeatability and reproducibility for offline scanning by FT-NIR spectrometer. Similarly the wavelength selected for the online scanning were $760 \mathrm{~nm}$ i.e. band of water, $680 \mathrm{~nm}$ i.e. band of chlorophyll and $913 \mathrm{~nm}[6]$ band of sucrose.

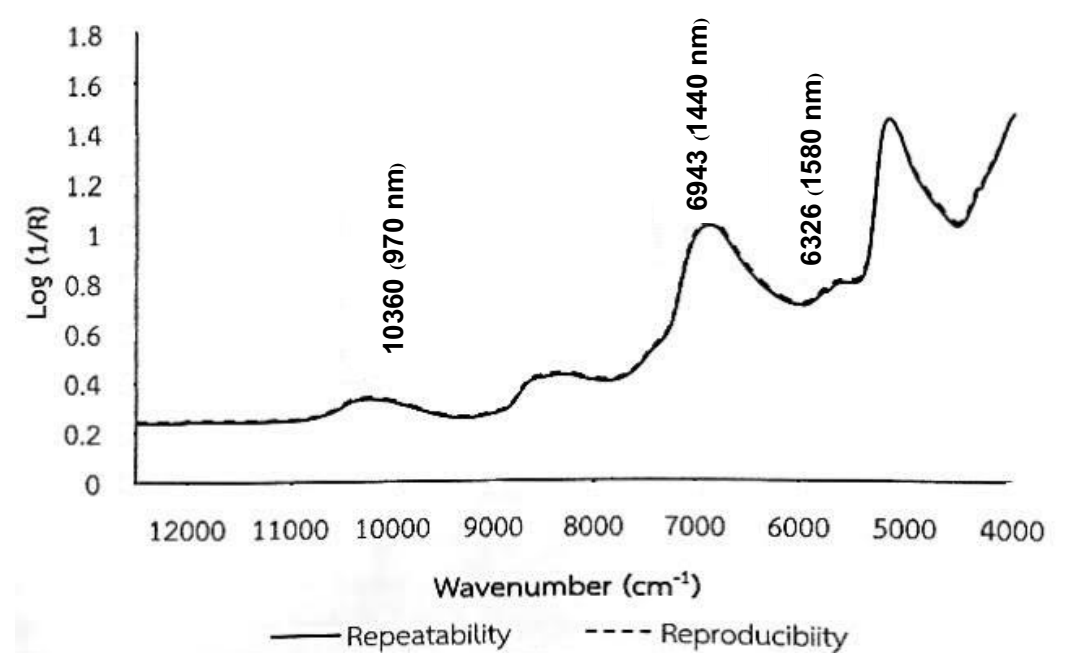

Fig.1. The average spectra of mango samples of FT-NIR spectrometer. 


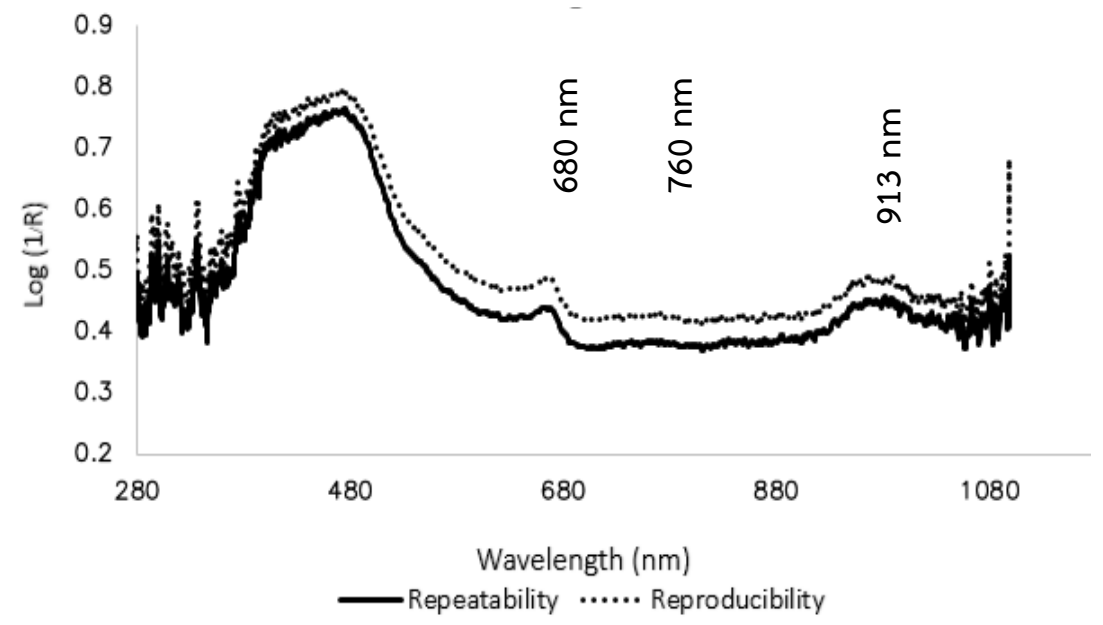

Fig. 2. The average spectra of mango samples of UV-VIS-NIR spectrometer.

\subsection{Precision of reference laboratory}

Table 1 shows repeatability indicates the precision of spectrometer. Low repeatability value indicated high precision of scanning. Reproducibility indicates the homogeneity of mango peel and pulp. Low reproducibility indicates high homogeneity of mango peel and pulp.

Table 1. Repeatability and reproducibility of scanning for mango by FT-NIR and UV-VIS NIR.

\begin{tabular}{|c|c|c|c|}
\hline \multirow{2}{*}{ Sample } & NIR & Repeatability & Reproducibility \\
\hline \multirow{2}{*}{ Mango } & FT-NIR & 0.00191 & 0.00323 \\
\cline { 2 - 4 } & UV-VIS NIR & 0.00529 & 0.03561 \\
\hline
\end{tabular}

Table 2 shows repeatability of reference test and $\mathrm{R} 2 \max$ of TSS and $\mathrm{pH}$.

Repeatability of reference test indicate precision of reference method. Low repeatability of reference test indicate high precision of reference method. $R^{2} \max$ indicate $R^{2}$ that there is only an error of reference methodtest and no error from NIR scanning and other.

Table 2. Repeatability of reference and $\mathrm{R}^{2} \mathrm{MAX}$ of total soluble solids and $\mathrm{pH}$ measured.

\begin{tabular}{|c|c|c|}
\hline Measured & $\begin{array}{c}\text { Repeatability of } \\
\text { reference_test }\end{array}$ & $\mathbf{R}^{2}$ MAX \\
\hline Total soluble solids & 0.2657 & 0.9825 \\
\hline $\mathrm{pH}$ & 0.0827 & 0.9504 \\
\hline
\end{tabular}




\section{Conclusions}

The repeatability and reproducibility of scanning indicate the precision of FT-NIR spectrometer and UV- VIS NIR spectrometer. Repeatability of reference test and $\mathrm{R}^{2}$ MAX indicate the error of the methods for reference test of TSS and $\mathrm{pH}$ which were only $2 \%$ and $5 \%$, respectively. The finding confirms that the NIR prediction model for TSS and $\mathrm{pH}$ should be developed further. However, the FT-NIR spectrometer is offline measurement while the UV-VIS NIR spectrometer could be applied for online measurement.

The author thanks Department of Agricultural Engineering, Faculty of Engineering, King Mongkut's Institute of Technology Ladkrabang for laboratory supports.

\section{References}

1. Department of Agriculture.Mango Planting Guide.[Online].Available: http://www.phitsanulok.doae.go.th/2016/images/amper/KMMango1.pdf. (2019, October)

2. Ministry of Commerce. Thai export market. [Online]. Available: http://tradereport.moc.go.th/Report/Default.aspx?Report=MenucomRecode\&ImExTyp $\mathrm{e}=1$ \&Lang=Th. (2019, October)

3. Agriculture plants.Golden Nam Dok Mai Mango.[Online].Available : https://puechkaset.com/.(2019,October)

4. S. Panmanas, M. Tanaka, T. Kojima, T, Ph. Williams. J Food Eng.112, 218 (2012)

5. Jr. Workman, L. Weyer, Boca Raton, (2008)

6. B.G. Osborne, T. Fearn, P. H. Hindle, Longman scientific and technical (1993) 